\title{
GPPS-TC-2019-0008
}

\section{Numerical Investigation of Heat Transfer in the Near Critical Point Applications}

\author{
Setareh Nakhostin ${ }^{1}$ \\ setareh.nakhostin@student.lut.fi \\ School of Energy Systems \\ Lappeenranta, Finland
}

\author{
Alireza Ameli \\ alireza.ameli@lut.fi \\ Laboratory of Fluid Dynamics \\ Lappeenranta, Finland
}

\author{
Teemu Turunen-Saaresti \\ teemu.turunen-saaresti@lut.fi \\ Laboratory of Fluid Dynamics \\ Lappeenranta, Finland
}

\begin{abstract}
Using supercritical $\mathrm{CO}_{2}\left(\mathrm{SCO}_{2}\right)$ as a working fluid in the Brayton cycle achieves relatively high thermal efficiency at lower turbine inlet temperature. However, on the account of the fact that using supercritical $\mathrm{CO}_{2}$ in the vicinity of critical point changes the default design rules, flow characteristics and boundary layer behaviour inside heat exchanger should be investigated to optimize the design parameters. The effect of the friction factor coefficient on the heat transfer and flow behaviour inside the heat exchanger is studied. The special attention is paid on the analysis of the pressure drop inside the heat exchanger. In this paper, a horizontal heated pipe with different mass flow rates, heat fluxes and boundary conditions have been numerically investigated. Different turbulence models to compute the friction factor coefficient near the critical point have been compared and the most accurate approach has been suggested. Comparing different friction factor correlations with CFD results indicated that the accuracy of different correlations is varied based on Reynolds number range and heat flux.
\end{abstract}

\section{INTRODUCTION}

Using supercritical $\mathrm{CO}_{2}$ Brayton cycle is widely considered in power cycles due to its superior advantages compared to conventional cycles. Supercritical $\mathrm{CO}_{2}$ cycle has been investigated in details by Dostal [1] and Sandia National laboratories [2] used for different heat sources including, solar, bio mass and fossil. Also, the promising $\mathrm{CO}_{2}$ working fluid for the closed cycle was studied by Dostal [1] due to its advantages over the other working fluids. Besides, compared to the refrigerants, $\mathrm{CO}_{2}$ is non-toxic, nonflammable, environmental friendly and abundant. Thermophysical properties of $\mathrm{CO}_{2}$ near its critical point show unique characteristics. Isobaric specific heat reaches to the maximum value at critical point, causes sharp differences thermophysical characteristics.

The Direct numerical simulation (DNS) for heat transfer investigation inside a small horizontal pipe (using $\mathrm{SCO}_{2}$ working fluid) with 1 and $2 \mathrm{~mm}$ diameters was done for the first time by Chu et al. [3]. In their study, the inlet Reynolds number was considered to be 5400 and the inlet temperature considered less than critical temperature. Results showed that the temperature of top wall is higher than bottom wall in both cases. The $2 \mathrm{~mm}$ pipe experienced stronger buoyancy effect than the smaller pipe. In addition, buoyancy caused the nonuniform circumferentially friction factor coefficient. Also, flow stratification was observed and the low density flow placed near the top wall due to the buoyancy force. Saeed et al. [4] numerically investigated the friction factor of $\mathrm{SCO}_{2}$ inside a zigzag channel printed circuit heat exchanger (PCHE). A Wide range of Reynolds numbers between 2500 to 30000 were used for their numerical computations. The CFD results of the friction factor compared to some friction correlations, and the best agreement on the cold side was achieved using the correlation proposed by $\mathrm{Ngo}$ et. al [5] and $\mathrm{Kim}$ et.al [6]. However, on the hot side the correlation proposed by Kim et al. [6] showed the most accurate result. In research by Nikitin et al. [7] thermophysical characteristics of $\mathrm{SCO}_{2}$ including heat transfer and pressure drop inside PCHE were studied numerically and experimentally. For achieving the local heat transfer and pressure drop, an empirical correlation was proposed. The range of Reynolds number was considered between 2800 to 12100. The main achievement was proposing the empirical correlations for PCHE in order to predict the heat transfer coefficient as well as the pressure drop factor.

${ }^{1}$ Corresponding author. 
Wang et al. [8] numerically investigated the effect of the turbulence models near the critical point inside a $\mathrm{SCO}_{2}$ horizontal cooling pipe with diameter of $22.14 \mathrm{~mm}$. In numerical simulations, four different $\mathrm{k}-\varepsilon$ turbulence models were compared, of which the AKN with low Reynolds number had the best match with the experimental data proposed by Adebiyi and Hall [9]. The results showed, by increasing the heat flux, buoyancy effect became stronger. Consequently, the temperature difference between top and bottom walls increased.

Adebiyi and Hall [9] experimentally investigated the $\mathrm{SCO}_{2}$ heat transfer in horizontal pipe. According to the results, the heat transfer enhancement was observed at the bottom of the pipe, and the buoyancy effect caused a reduction in the heat transfer coefficient near the top wall. Another experimental study about the effect of the buoyancy force on the heat transfer inside a horizontal tube with supercritical water was introduced by Bazargan et al. [10]. In experimental condition pressure range was between 23 to $27 \mathrm{MPa}$, constant heat flux: $310 \mathrm{KW} / \mathrm{m}^{2}$ and mass flux range was from 330 to 1230 $\mathrm{kg} / \mathrm{m}^{2} \mathrm{~s}$. They found out in buoyancy free conditions, the difference between experimental data and available empirical correlations would be high. Therefore, a new correlation was recommended to be investigated. Liao et al. [11] measured experimentally heat transfer in $\mathrm{SCO}_{2}$ horizontal mini/micro cooled channels. The buoyancy effects in pipe diameters from $0.5 \mathrm{~mm}$ to $2.16 \mathrm{~mm}$ were studied. Reynolds number was up to 100000 . The result showed the importance of buoyancy in all tests. However, by reducing the tube diameter, buoyancy became weaker, and the Nusselt number decreased. Dang and Hihara [12] investigated heat transfer in cooling $\mathrm{SCO}_{2}$ horizontal pipe experimentally. The inner tube diameter was between $1 \mathrm{~mm}$ to $6 \mathrm{~mm}$. In their study the effect of heat flux, mass flux and pressure were investigated on parameters like heat transfer coefficient and pressure drop. The experimental measured heat transfer coefficient compared to various existed correlations. As a result, the modified Gnielinski [13] correlation was introduced with accuracy of $20 \%$ over experimental data. In addition, the dependency of increasing mass flux and pressure drop were observed. Also, in case of temperature lower than pseudocritical temperature, pressure drop and inlet pressure were independent and under condition with temperature higher than pseudocritical temperature, increasing pressure led to decrease pressure drop. Walisch et al. [14] measured heat transfer coefficient experimentally in $\mathrm{SCO}_{2}$ horizontal, vertical and inclined pipe with inner diameter $10 \mathrm{~mm}$. Wall temperature was considered constant and Reynolds number range for turbulent flow was between 2300 and 100000 . For defined geometries, thermophysical properties like density and heat capacity variation affected the heat transfer. The thermophysical properties near the critical point showed the similar behaviour in pseudo-critical line with lower degree. According to Wang et al. [15] the friction factor in $\mathrm{SCO}_{2}$ horizontal pipe with considering different pressure and temperature range inside the pipe examined experimentally. The Reynolds number range was considered from 200 to 2000000. Experimental validation has been carried out in
$\mathrm{SCO}_{2}$ pipe and compared with 15 friction factor coefficient correlations. None of the correlations were matched with experimental data. The modified calculation model for friction factor coefficient was proposed with $1.94 \%$ average error over the experimental data. Moreover, $\mathrm{SCO}_{2}$ density and viscosity were affected by temperature and pressure, consequently, the impact of Reynolds number near the critical point was observed sharply. Also, by increasing Reynolds number in turbulence flow region, the friction factor coefficient reduced.

In this paper, the turbulent flow of supercritical $\mathrm{CO} 2$ in heated horizontal pipe is investigated numerically. The different Reynolds numbers and heat fluxes were simulated and different turbulence models were compared. Especial attention was paid on the friction coefficient and simulated friction coefficients were compared to different existing friction factor correlations. The most accurate turbulence model and friction factor coefficients were suggested.

\section{COMPUTATIONAL DETAILS}

\section{Geometry and boundary condition}

In this study the experimental results of Adebiyi and Hall investigation [9] are used to validate heat transfer characteristics and turbulence models. In experimental investigation, a pipe with about $4 \mathrm{~m}$ length and inner diameter of $22.14 \mathrm{~mm}$ was tested. As it is shown in figure 1, the pipe is divided into two parts including, adiabatic and heating part. The adiabatic part was added to ensure that the flow profile is fully developed before entering the heating part. Heating is uniform throughout the tube.

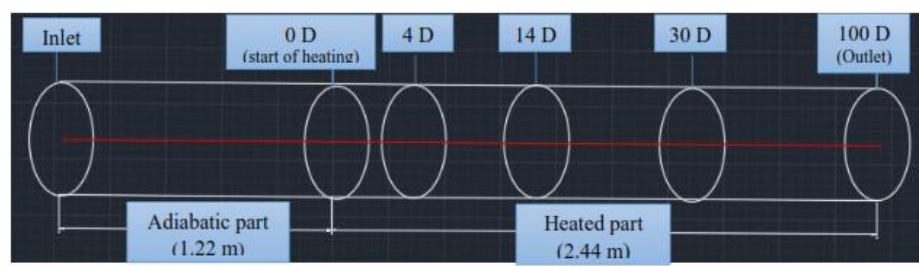

Figure 1 Schematic of the numerical model

According to experimental conditions shown in table 1, four test conditions are numerically studied. The range of mass flow rate is from 0.151 to $0.080 \mathrm{~kg} / \mathrm{s}$. The cross section of mesh is shown in figure 2. The grid resolution is fine enough to ensure $\mathrm{y}+<1$.

The mesh independency study was performed (figure 3) using three different grid resolutions; 500000,750000 and 1300000 cells. The grid with 1.3 million cells seems to be fine enough for giving mesh independent results.

ANSYS CFX was used as a solver for numerical computation [30]. Regarding the boundary conditions, pressure and temperature were set for inlet and mass flow rate was set for the outlet. Walls are considered as no slip, with adding constant heat flux throughout the heating part. Symmetric boundary condition was used to model half of the pipe in order to save the computational time. 
Table 1 Experimental conditions

\begin{tabular}{|c|c|c|c|c|c|}
\hline $\begin{array}{c}\text { Test } \\
\text { code }\end{array}$ & $\begin{array}{c}\text { Mass } \\
\text { flow } \\
\text { rate } \\
(\mathrm{kg} / \mathrm{s})\end{array}$ & $\begin{array}{c}\text { Inlet bulk } \\
\text { temperature } \\
\left({ }^{\circ} \mathrm{C}\right)\end{array}$ & $\begin{array}{c}\text { Average } \\
\text { heat flux } \\
\left(\mathrm{kW} / \mathrm{m}^{2}\right)\end{array}$ & $\begin{array}{c}\text { Outlet bulk } \\
\text { temperature } \\
\left({ }^{\circ} \mathrm{C}\right)\end{array}$ & $\begin{array}{c}\text { Test } \\
\text { pressure } \\
\left(\mathrm{MN} / \mathrm{m}^{2}\right)\end{array}$ \\
\hline \hline 1.1 & 0.151 & 15.9 & 5.3 & 18.1 & 7.586 \\
\hline 1.2 & 0.148 & 15.4 & 15.1 & 21.3 & 7.59 \\
\hline 2.1 & 0.0773 & 14.2 & 5.2 & 18.4 & 7.603 \\
\hline 3.1 & 0.080 & 19.7 & 5.1 & 23.2 & 7.607 \\
\hline
\end{tabular}

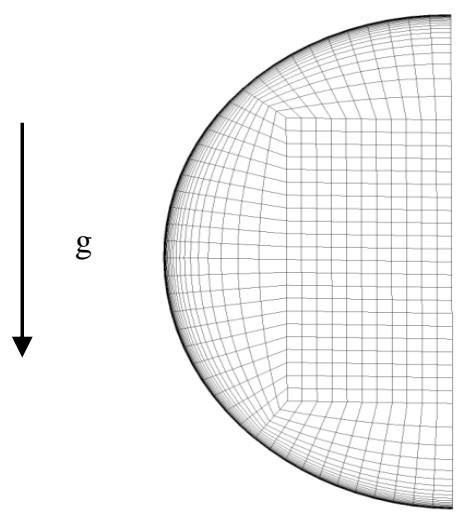

Figure 2 Cross section of mesh grid used in
simulation

To capture the real gas behaviour of the fluid in the supercritical region, real gas properties table (RGP) was coupled with the solver. The RGP table contains nine major properties such as, specific entropy/enthalpy, speed of sound, specific volume, specific heat at constant pressure and constant volume, dynamic viscosity, thermal conductivity, and finally partial derivative of pressure with respect to specific volume at constant temperature [16]. Fluid properties were taken from NIST REFPROP data base [16], using Span and Wagner equation of state (EOS) [17]. Span and Wagner EOS is based on Helmholtz energy and has been developed specifically for $\mathrm{CO}_{2}$ [18]. The high resolution schemes were set to discretize the equations. Energy, mass and momentum imbalances were checked to ensure the convergence of the simulations. Besides, root mean square (RMS) of mass, momentum, energy and turbulence parameters were less than $10^{-5}$.

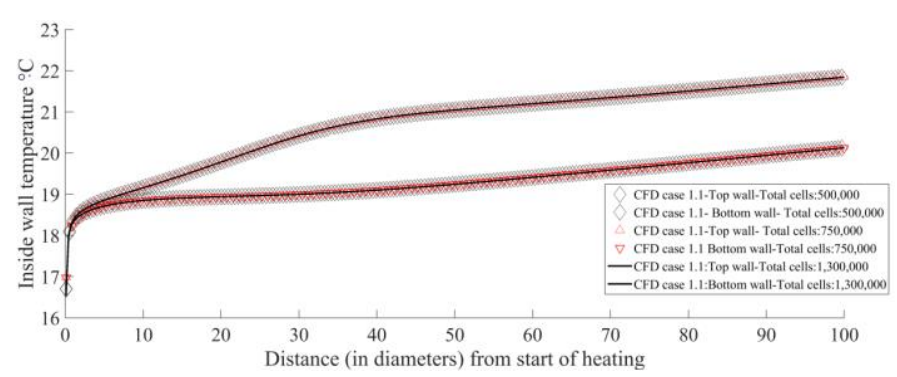

Figure 3 Mesh dependency test for CFD case 1.1 with coarse mesh (total cells: 500000 ) and fine mesh (total cells: 1300000)

\section{VALIDATION OF NUMERICAL COMPUTATION}

In the experimental measurements [9], to achieve the temperature distribution along the tube, the welded thermocouples with various angles were placed at top and bottom part of the tube wall.

To find out the most accurate turbulence model for the CFD simulation in this case, four different turbulence models are examined under test 1.1 experimental conditions (see table 1).

In figure 4, the results of the compared turbulence models including: shear stress transport (k- $\omega$ SST ), k- $\varepsilon$ EARSM, Omega Reynolds Stress (ORS) and standard k- $\varepsilon$, are shown.

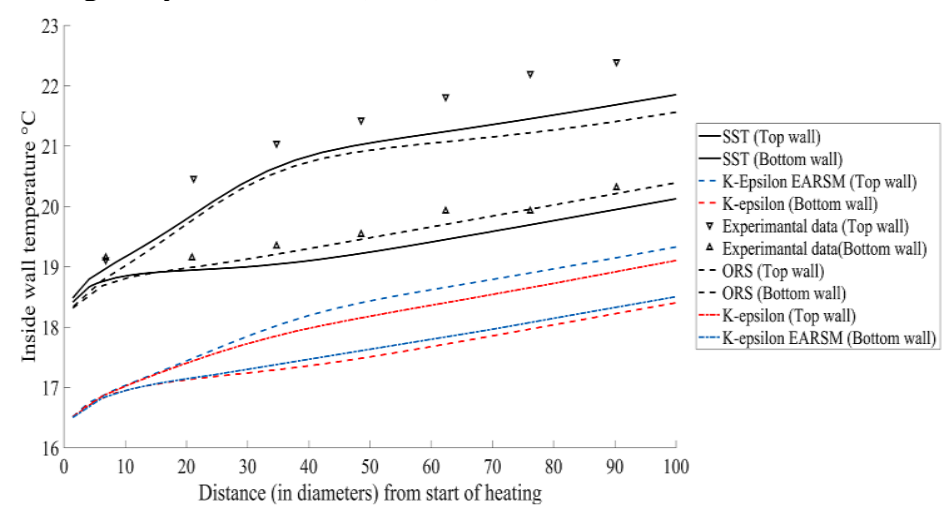

Figure 4 Validation of wall temperature distribution, simulated by different turbulence models against Adebiyi and Hall experimental results (considering the starting point of heated wall $x / d=0$ ).

Two turbulence models k- $\varepsilon$ EARSM and k- $\varepsilon$ standard showed high degree of discrepancy over the experimental results. On the other hand, the SST has the best agreement with experimental data followed by ORS model. Therefore, the SST turbulence model has been used for the rest of the investigations in this study.

\section{RESULTS AND DISCUSSION Wall temperature distribution}

According to results, shown in figure 5, in all CFD cases the top walls have higher temperature than bottom walls due to the buoyancy effect, and the highest temperature is observed at the top wall of CFD case 1.2 with the highest heat flux $\left(\mathrm{q}=15100 \mathrm{~W} / \mathrm{m}^{2}\right)$. In test cases $1.2,2.1$ and 3.1 , the sharp temperature changes are observed at the start of heating section, following by rather constant temperature increment trend. However, in CFD case 1.1 with the highest mass flow rate, this sharp change has not been observed. Moreover, the best agreement between CFD result and the experimental data for both top and bottom walls is achieved in case 1.1 due to relatively lower heat flux and consequently smaller buoyancy effect followed by case 1.2. The CFD results of case 2.1 and 3.1 show high degree of discrepancy over experimental results on top walls but the bottom walls in both cases are still in a good agreement. In CFD case 1.1, the heat flux is lowest and the temperature difference between 
top and bottom wall is not rather significant. In another word, the effect of the buoyancy force is not noticeable and consequently, there is less complexity in the flow.

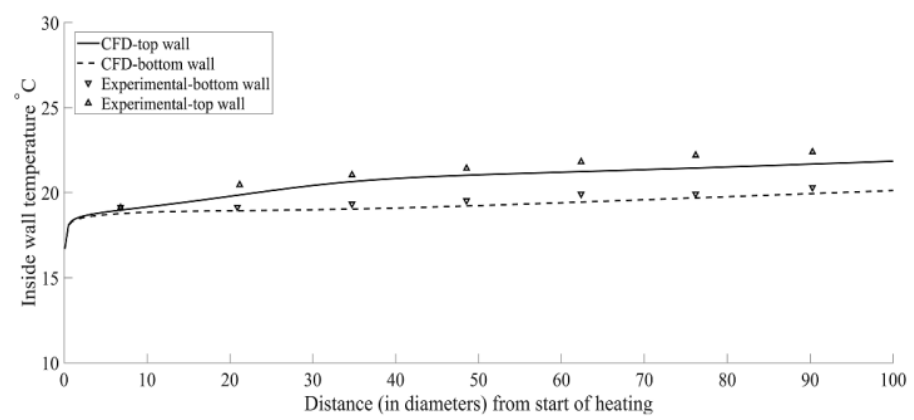

a) Case 1.1

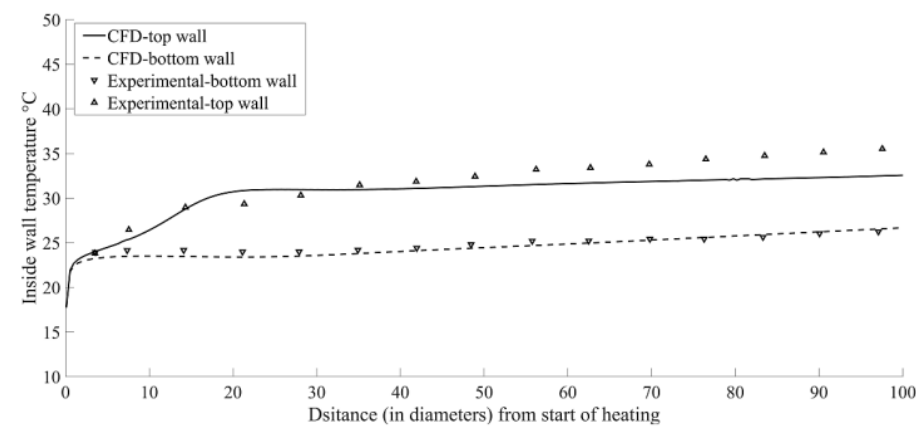

b) Case1.2

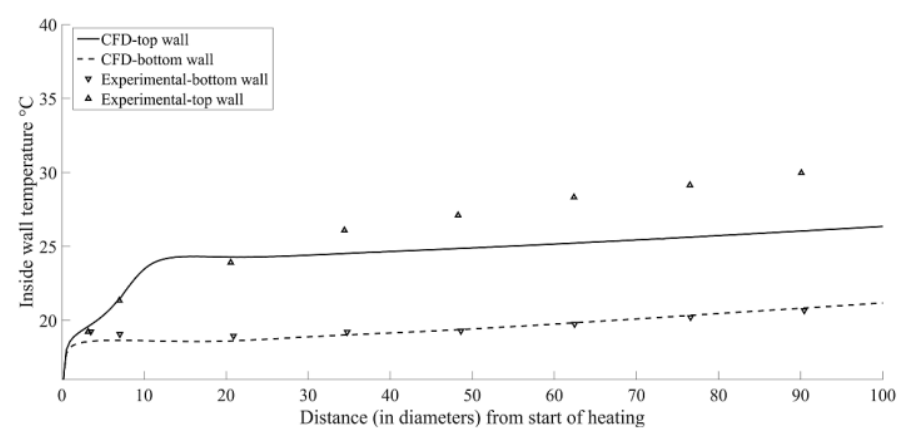

c) Case 2.1

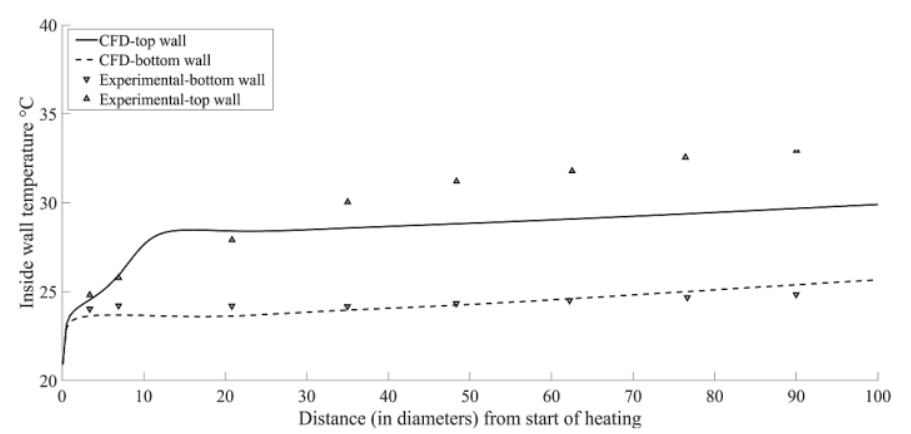

d) Case 3.1

Figure 5 Temperature distribution of numerical results based on SST turbulence model against experimental results in four test conditions

\section{Heat transfer coefficient}

The computed heat transfer coefficient in CFD simulation is based on equation 1, where, $q$ is the heat flux, $T_{w}$ expresses the wall temperature and $T_{b}$ is the bulk temperature.

$$
h=\frac{q}{\left(T_{w}-T_{b}\right)}
$$

According to results of the figure 6 , the heat transfer coefficient at the bottom walls are higher than the top walls in all CFD cases, which can be referred to the higher temperature difference between the top walls and the bulk temperature than the bottom walls and bulk temperature. Therefore, with considering the constant heat flux, the heat transfer coefficients on top walls are lower than the bottom walls. According to the figure 6 , in all cases, the heat transfer coefficients are changed sharper at the top walls while the changes are smoother at the bottom walls. This change is observed more significant in CFD case 1.2 with highest heat flux compared to other cases. However, the heat transfer coefficient trends in all simulated cases remain constant after around 15D-20D from start of the heating.

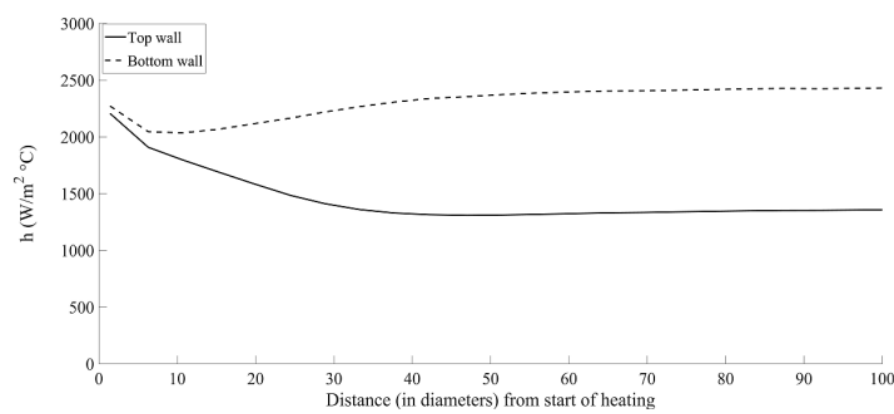

a) Case 1.1

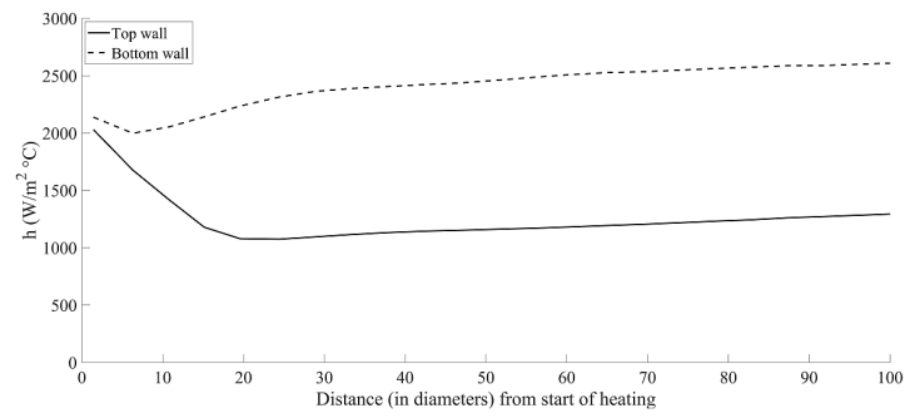

b) Case 1.2 


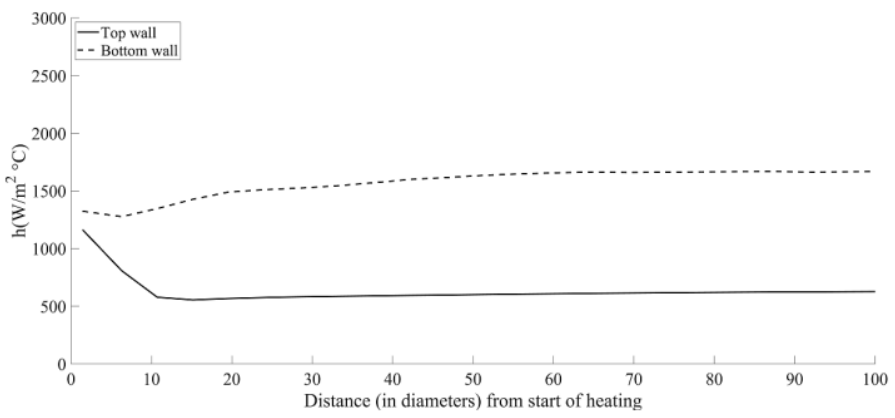

c) Case 2.1

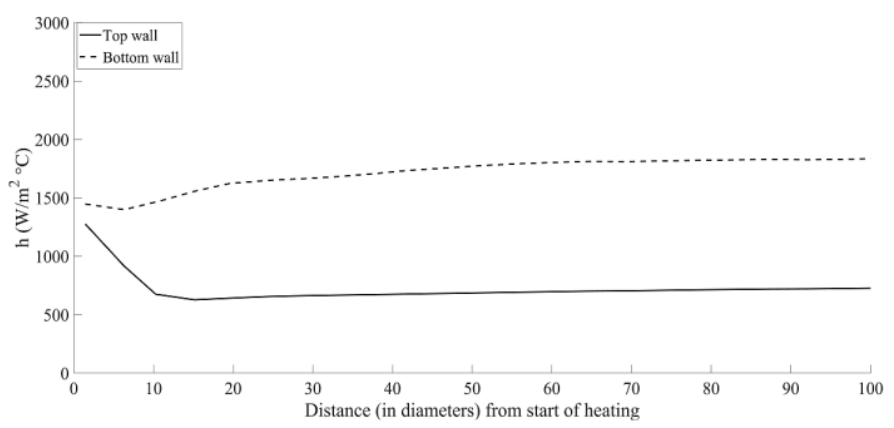

d) Case 3.1

Figure 6 Heat transfer distribution of numerical results based on SST turbulence model in four test conditions.

\section{Friction factor Coefficient}

The fluid flow along the tube is influenced by viscous, friction and buoyancy forces. Studying the friction factor coefficient is the major parameter to determine the pressure drop inside the heat exchanger. The generic equation of friction factor is expressed by equation 2 .

$$
\mathrm{C}_{\mathrm{f}}=\frac{\tau_{w}}{\frac{1}{2} \rho U^{2}}
$$

Where, $\tau_{\mathrm{w}}$ is the wall shear stress, $\rho$ is the bulk density and $U$ is the bulk fluid velocity.

The friction factor coefficients along the pipe at the top and bottom walls are shown for each CFD case in figure 7 . The value of friction factor coefficient at the bottom wall is higher than the top wall in all CFD cases. In fact, shear stress is higher at the bottom wall. In figure 7, Friction factor coefficient of top and bottom walls start with sharp changes at the start of heating and then continue with a rather constant trend. As it is observed, the highest change are observed in CFD cases 2.1 and 3.1 with lower mass flux compared to other cases.

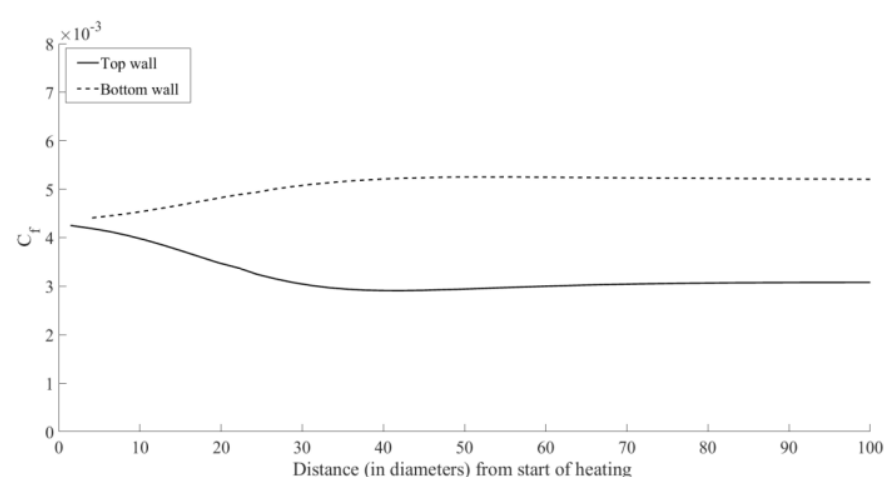

a) Case 1.1

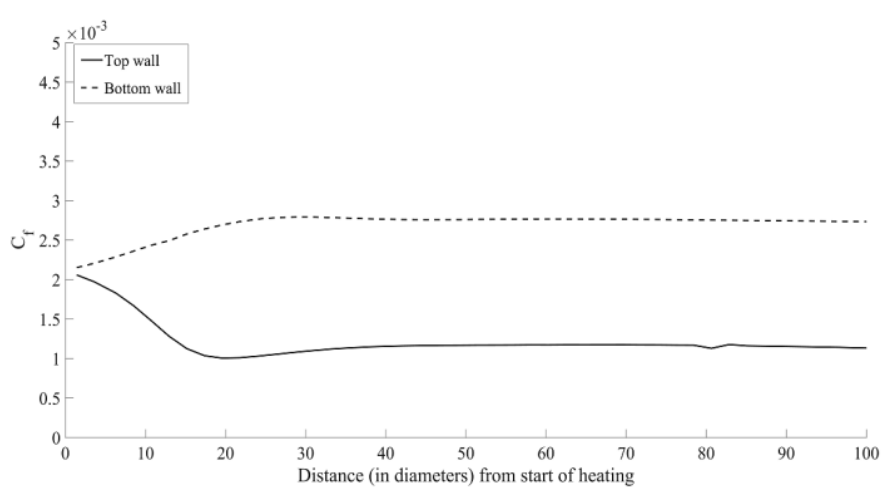

b) Case 1.2

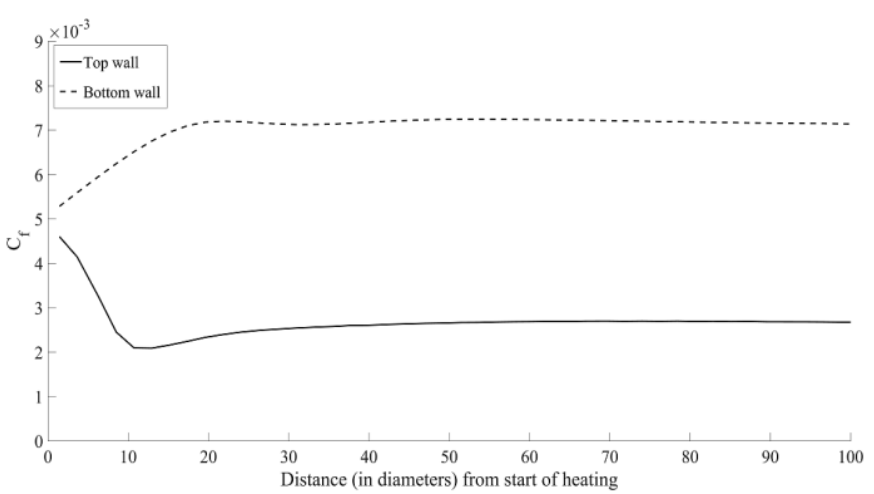

c) Case 2.1

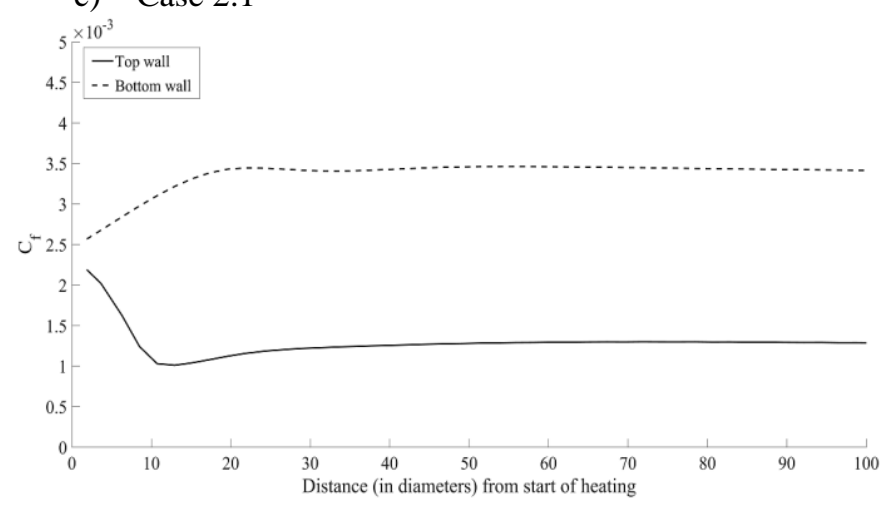

d) Case 3.1

Figure 7 Friction factor coefficient of numerical results based on SST turbulence model in four test conditions 
Furthermore, the averaged friction factors of the top and bottom walls in adiabatic and heated parts are calculated individually for each test case (see table 2). The higher change is observed from case 1.1 to 1.2 due to increasing heat flux from CFD case 1.1 to 1.2 , which causes strong buoyancy force as a result of raising temperature difference between top and bottom wall. Consequently, the sharp change is observed at the beginning of heated part in case 1.2. On the other hand, mass flux reduction from case 1.2 to 2.1 creates sharp value change related average friction factor coefficient from adiabatic to heated section. The important achievement by analysing data of table 2 is that, the friction factor change is more dependent on heat flux than the mass flux; meaning, referring to CFD condition, heat flux increases from case 1.1 to 1.2 , where calculated friction factor change percentage (from adiabatic to heated section) highly increased (from 5.8 to 11.7). However, although from Case 1.1 to 2.1 and 3.1 mass flux reduces; the calculated change percentage has not changed significantly.

Table 2 Comparison of average friction factor in heating wall with adiabatic wall for numerical cases

\begin{tabular}{|c|c|c|c|}
\hline Case code & $\begin{array}{c}\text { Average of } \mathrm{C}_{\mathrm{f}} \\
\text { (Heating } \\
\text { wall) }\end{array}$ & $\begin{array}{c}\text { Average of } \mathrm{C}_{\mathrm{f}} \\
\text { (Adiabatic } \\
\text { wall) }\end{array}$ & $\begin{array}{c}\text { Changes } \\
(\%)\end{array}$ \\
\hline \hline 1.1 & 0.0041 & 0.0044 & 5.8 \\
\hline 1.2 & 0.0039 & 0.0044 & 11.7 \\
\hline 2.1 & 0.0048 & 0.0050 & 4.5 \\
\hline 3.1 & 0.0046 & 0.0049 & 5.2 \\
\hline
\end{tabular}

\section{VALIDATION OF SEVERAL FRICTION FACTOR COEFFICIENT CORRELATIONS AGAINST CFD RESULTS}

In this section, 12 well-known friction factor correlations are compared with CFD results. Table 3 shows correlations and related equations with respect to the employed Reynolds number range. Blasius (1913) [19] correlation can be considered the simple one, which is based on first principal of non-Newtonian fluid flow. Filonenko [20] is gained from developed Darcy equation. For tubes with small roughness elements and turbulent flow, Blasius[19] and Filonenko[20] friction factor correlations are proposed. Wilcox correlation can be found out in [22]. The developed equation of Prandtle[23] is Prandtle (Denn) [23]. Prandtle-Schlichting correlation can be found in [24]. Kempf-Karman and Granville are extracted from [25][26]. Morrison correlation can be used for smooth pipe employing all range of Reynolds number [27].
Table 3 List of friction factor correlations used in validation

\begin{tabular}{|c|c|c|}
\hline Data source & Correlation & $\begin{array}{c}\text { Range of } \\
\text { Re }\end{array}$ \\
\hline $\begin{array}{ll}\text { Blasius } & {[19]} \\
(1913) & \\
\text { Blasius R } & {[21]} \\
\end{array}$ & $\begin{array}{l}C_{f}=0.316(\operatorname{Re})^{-0.25} \\
C_{f}=0.079(\operatorname{Re})^{-0.25}\end{array}$ & $\operatorname{Re} \leq 10^{5}$ \\
\hline Filonenko [20] & $C_{f}=(1.82 \log (R e)-1.64)^{-2}$ & $\begin{aligned} 10^{4} & \leq \mathrm{Re} \leq 5 \\
& \times 10^{6}\end{aligned}$ \\
\hline $\begin{array}{ll}\text { Wilcox } & {[22]} \\
(1995) & \\
\text { Wilcox } & {[22]} \\
\end{array}$ & $\begin{array}{l}C_{\mathrm{f}}: 1 / \sqrt{\mathrm{f}}=-2 \log (2.51 / \operatorname{Re} \sqrt{\mathrm{f}}) \\
\text { Cf: } 0.045\left(\operatorname{Re}^{-0.25}\right)\end{array}$ & $\operatorname{Re}>3000$ \\
\hline$[19]$ & $\mathrm{C}_{\mathrm{f}}=0.0018+0.152(\mathrm{Re})^{-0.35}$ & $\mathrm{Re}>3000$ \\
\hline Jansen & $C_{f}=0.0412(\operatorname{Re})^{-0.1925}$ & $\mathrm{Re}>3000$ \\
\hline $\begin{array}{l}\text { Prandtl } \quad[23] \\
(1927)\end{array}$ & $C_{f}=0.074(\operatorname{Re})^{-0.2}$ & $\operatorname{Re}>4000$ \\
\hline $\begin{array}{l}\text { Prandtl- } \\
\text { Schlichting } \\
(1932)\end{array}$ & $\mathrm{C}_{\mathrm{f}}=0.455 \log (\mathrm{Re})^{-2.58}$ & $\mathrm{Re}>4000$ \\
\hline $\begin{array}{l}\text { Kempf-Karman } \\
(1951) \quad[25]\end{array}$ & $\mathrm{C}_{\mathrm{f}}=0.055(\mathrm{Re})^{-0.182}$ & $\operatorname{Re}>3000$ \\
\hline $\begin{array}{l}\text { Granville } \\
(1977) \quad[26]\end{array}$ & $\begin{array}{l}\mathrm{C}_{\mathrm{f}}=0.0776(\log (\mathrm{Re})-1.88)^{-2} \\
+60(\mathrm{Re})^{-1}\end{array}$ & $\operatorname{Re}>3000$ \\
\hline Genielinski [13] & $\mathrm{C}_{\mathrm{f}}=(0.79 \log (\mathrm{Re})-1.64)^{-2}$ & $\operatorname{Re}>3000$ \\
\hline $\begin{array}{l}\text { Prandtle (Denn) } \\
(1927) \quad[28]\end{array}$ & $\mathrm{Cf}=0.255 \log (\mathrm{Re})^{-2.5}$ & $\begin{array}{l}3000 \leq \mathrm{Re} \\
\leq 5 \times 10^{6}\end{array}$ \\
\hline Morrison [27] & $\mathrm{C}_{\mathrm{f}}=\frac{\left(0.0076 *(3170 / R e)^{\wedge} 0.165\right.}{\left.\left(1+(3170 / R e)^{\wedge} 7\right)\right)+16 / R e}$ & $10^{2} \leq \operatorname{Re} \leq 10^{7}$ \\
\hline
\end{tabular}

Figure 8, represents the validation of CFD results against 2 experimental data, including Adebiyi and Hall [9] and DangHihara [12] as well as 12 existed friction factor correlations. In fact, the CFD results are calculated based on the average friction factor coefficient of top and bottom wall for each CFD case individually. The Dang and Hihara [12] experimental results have been investigated for horizontal pipe with $2 \mathrm{~mm}$ inner tube, which used $\mathrm{SCO}_{2}$ working fluid. The experimental conditions are included $30^{\circ} \mathrm{C}$ inlet temperature range from $30^{\circ} \mathrm{C}$ to $70^{\circ} \mathrm{C}$, mass flux is 800 $\mathrm{kg} / \mathrm{m}^{2} \mathrm{~s}$, heat flux is $12 \mathrm{KW} / \mathrm{m}^{2}$ and pressure drop range is from 30 to $70 \mathrm{MPa}$. The employed Reynolds number range in Dang -Hihara [12] is the same as CFD results.

The generic equation for calculating Reynolds number at start of heating section for each CFD cases is:

$$
\operatorname{Re}=\frac{\rho v D}{\mu}
$$


Where, $\rho$ is fluid density $\left(\mathrm{kg} / \mathrm{m}^{3}\right), v$ is fluid velocity $(\mathrm{m} / \mathrm{s}), \mathrm{D}$ is tube diameter $(\mathrm{mm})$ and $\mu$ determines fluid dynamic viscosity $(\mathrm{kg} / \mathrm{m} \mathrm{s})$.

According to figure 8 , range of Reynolds number is $9 \times 10^{4}$ $<\operatorname{Re}<12 \times 10^{4}$ with respect to average friction factor coefficient of each CFD case. It is observed that, the predicted friction factor coefficient by four friction factor correlations including: Blasius [19], Wilcox 1995 [22], Morrison [27] and Lee [19] are in the best agreement with CFD results in the studied Reynolds number range. It is worth mentioning that, Dang-Hihara [12] results, employed in the same CFD boundary condition and Reynolds number range, with except smaller tube diameter $(2 \mathrm{~mm})$ compared to numerical condition. CFD results showed the best agreement between Dang-Hihara [12] experimental results and the predicted friction factor coefficient using the Blasius $\mathrm{R}$ [21] and Genielinski [13] correlations.

The important interpretation from the results of figure 8 is that defining specific accurate friction factor correlation for special fluid flow can be depends on various parameters including Reynolds number and the operating conditions. Therefore, determining agreed general statement for the friction factor correlation with CFD results is not considered logical.

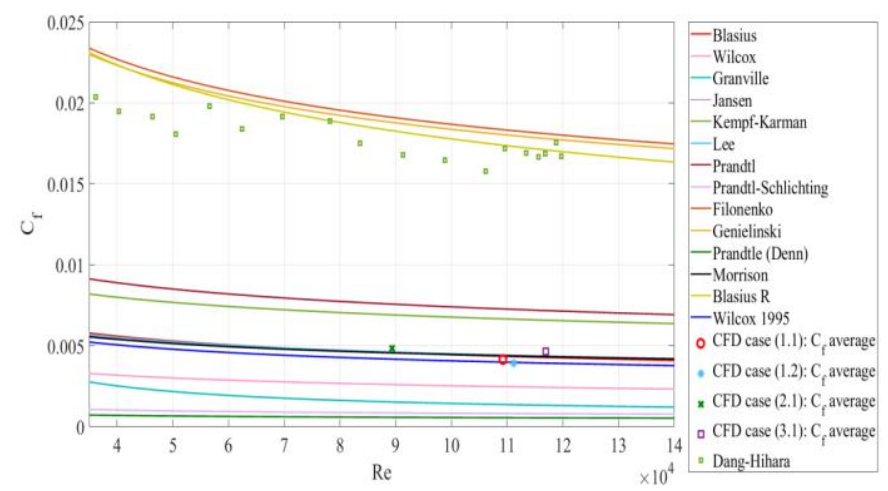

Figure 8 Validation of numerical results of friction factor coefficient (Averaged-top/bottom wall) against several friction factor correlations.

Figure 9, shows the top and bottom walls friction factor coefficients derived from the CFD results as well as comparison with the correlations. The CFD results of case 2.1 and 3.1 (considering the bottom wall with higher shear stress as well as lower temperature than top wall) are in good agreement with correlation proposed by Kempf-Karman [25]. However, the calculated friction factor coefficients of CFD cases 1.1 and 1.2 can be predicted rather closely using the Blasius [19], Morrison [27] and Lee [19] correlations. On the other hand, the same comparison for top wall shows that cases 1.2, 2.1 and 3.1 are in good agreement with the predicted friction factor using correlation proposed by Wilcox [22]. Also the friction factor of top wall in CFD case 1.1 with some degree of deviation has rather good agreement with predicted friction factor coefficient used Wilcox 1995 [22] correlation.

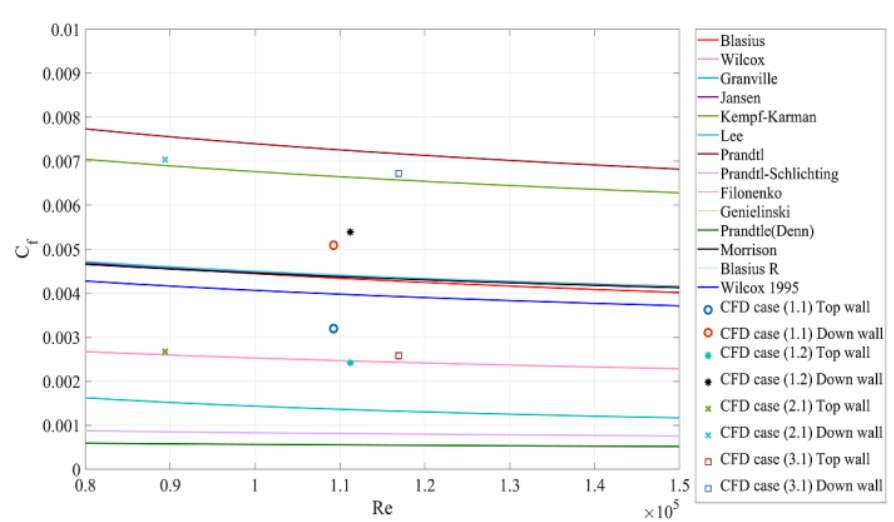

Figure 9 Validation of numerical results of friction factor coefficient (top/bottom wall) against best matched friction factor correlations.

\section{VELOCITY AND DENSITY CONTOURS}

Four cross sections from start of the heating to the outlet were named based on their distance in diameters (D) as 4D, 14D, 30D and outlet. The normalized velocity and density contours of the test case 1.2 at the defined cross sections are shown in figure 11 .

By applying a constant heat flux, the temperature difference between top and bottom walls increases along the pipe. Slightly after start of heating, at 4D, normalized velocity and density contours at the cross section are still uniform. While, by moving to the downstream, due to the temperature difference between top and bottom walls, the heated $\mathrm{CO}_{2}$ with lower density is pushed upward (near the round walls) and the flow with higher velocity moves closer to the bottom wall (in the middle of the pipe). These flow movements generate the secondary flow and vortexes. The direction of upward and downward flow on cross section are shown in figure 10 .

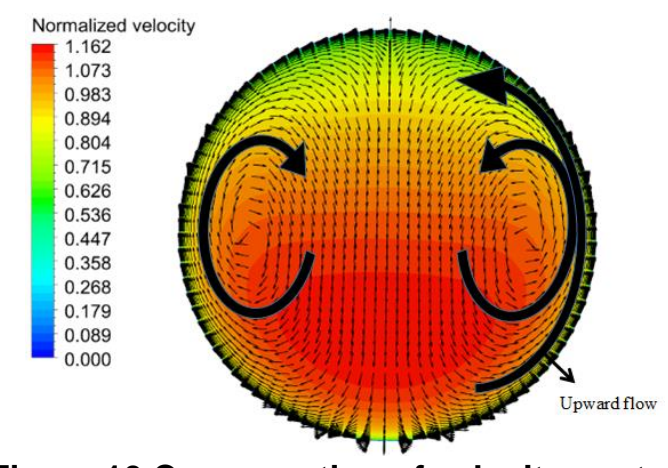

Figure 10 Cross section of velocity contour 


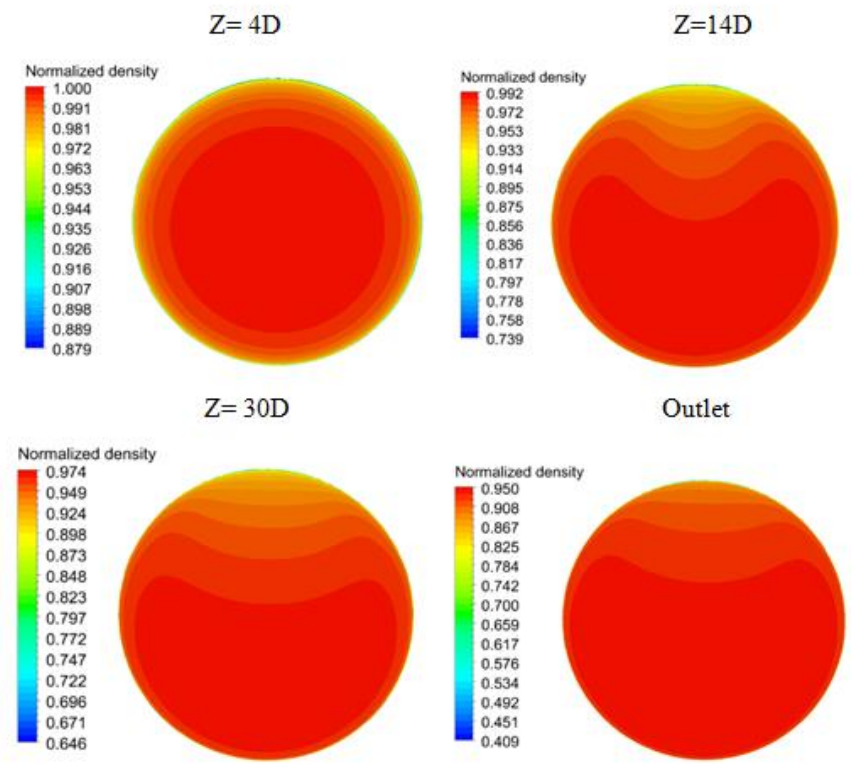

Test 1.2: Normalized density $\rho / \rho_{\text {in }}$
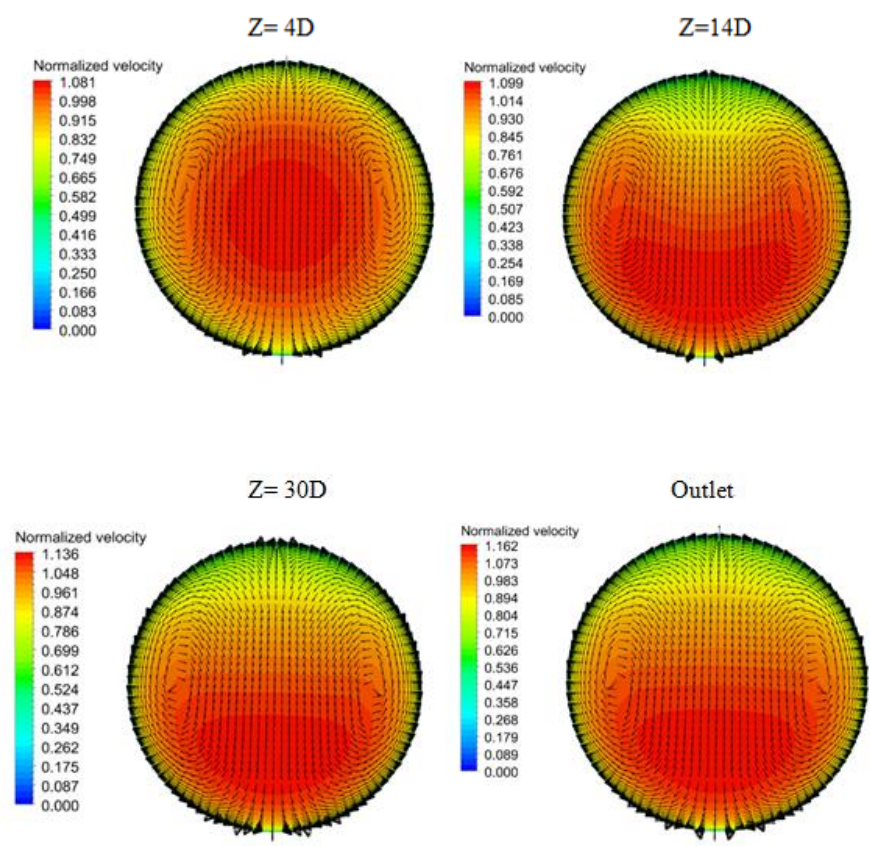

Test 1.2: Normalized velocity $U / U_{\text {in }}$

\section{Figure 11 Velocity and density contours of numerical results in 1.2 test condition}

\section{CONCLUSION}

In this paper, the thermophysical properties of $\mathrm{SCO}_{2}$, flow structure and friction coefficient in a heated horizontal pipe was investigated numerically. Different boundary conditions and heat fluxes were modelled and results were compared against the experimental data.

The major focus of this study was on analysing the friction factor coefficient, which is the most important factor to estimate the pressure drop inside heat exchangers. Adebiyi and Hall [9] experimental data was used as a reference to validate the numerical computations. By comparing different turbulence models including two-equation and Reynolds stress models, k- $\omega$ SST model showed the best agreement with experimental data.

The CFD results of temperature distribution, heat transfer and friction factor coefficients were validated against experimental results. By studying the heat transfer coefficient along the pipe at the top and bottom walls, heat transfer coefficient on bottom wall showed enhancement compared to top wall.

Calculated friction factor coefficient were compared against 12 well-known correlations obtained from the literature. It was noticed that, there is a difference in the values for the friction coefficient on the top and bottom sides of the heated part of the pipe. Top wall has smaller friction coefficient values due to lower velocity as a result of buoyancy force. The averaged values of the friction coefficients at the top and bottom sides were in a good agreement with three correlations (Wilcox 1995 [22], Blasius [21] and Morrison [27]). In conclusion, finding the best accurate friction factor correlation for the particular heating/cooling pipe can be depended on various parameters including Reynolds number and the tube diameter. Therefore, determining agreed general statement for the friction factor correlation with CFD results is not considered logical.

\section{REFERENCES}

[1] Dostal,V., Driscoll, M. J. , Hejzlar,. P., 2004. Advanced Nuclear Power Technology Program. A Supercritical Carbon Dioxide Cycle for Next Generation Nuclear Reactors.Doctoral thesis.MIT University.

[2] Steven A.Wright, Ross F. Radel "Operation and analysis of supercritical $\mathrm{CO}_{2}$ Brayton cycle" SANDIA report, 2010.

[3] Chu,X.\& Laurien,E.,2016. "Flow stratification of supercritical $\mathrm{CO}_{2}$ in a heated horizontal pipe. The journal of supercritical fluids, vol.116,no.172-189 pp.

[4] Saeed,M. \& Kim,M.H., 2017. Thermal and hydraulic performance of $\mathrm{SCO}_{2}$ PCHE with different fin configurations. Applied thermal engineering, vol. 127, no. August, pp. 975-985, 2017.

[5] Ngo,T.L., Kato,Y., Nikitin,K., Tsuzuki,N.,2006. New printed circuit heat exchanger with $\mathrm{S}$-shaped fins for hot water supplier. Experimental Thermal and fluid science, vol. 30, pp. 811-819.

[6] Kim, D. E., Kim, M. H., Eun cha.J, and Kim.S.O.,2008. Numerical investigation on thermal hydraulic performance of new printed circuit heat exchanger model . Journal of nuclear engineering and design. vol. 238, pp. 3269-3276.

[7] Nikitin,K., Kato,Y., and Ngo,L., 2006 .Printed circuit heat exchanger thermal - hydraulic performance in supercritical $\mathrm{CO}_{2}$ experimental loop..International Journal of refrigeration. vol. 29, pp. 807-814.

[8] Wang,J., Guan,Z., Gurgenci,H., Hooman,K., Veeraragavan,A., Kang,X.,2018. Computational investigations of heat transfer to supercritical $\mathrm{CO}_{2}$ in a large 
horizontal tube. Energy conversion and management., Vol.157, PP. 536-548.

[9] Adebiyi G. A. \& Hall, W. B.,1976. Experimantal investigation of heat transfer to supercritical pressure carbon dioxcide in a horizontal pipe.International journal of heat and mass transfer. vol. 19, pp. 715-720.

[10] Bazargan,M., Fraser,D.,Chatoorgan,V.,2005. Effect of bouyancy on heat transfer in supercritical water flow in a horizontal round tube. Journal of heat transfer.Vol. 127,no Aguest PP. 897-902.

[11] Liao,S.M, \& Zhao,T.S.,2002 . Measurements of Heat Transfer Coefficients from Supercritical Carbon Dioxide Flowing in Horizontal Mini / Micro channels. Journal of heat transfer, Vol. 124, pp. 413-419.

[12] Dang,C. \& Hihara,E.,2004. In-tube cooling heat transfer of supercritical carbon dioxide. Part 1 . Experimental measurement. International journal of refrigeration,vol. 27, pp. 736-747, 2004.

[13] Gnielinski,V.,1976. New equations for heat and mass transfer in turbulent pipe and channel flow. International chemical engineering.vol.16,no:pp.359-368.

[14] Walisch,T., Muller,M., Dorfler,W., Trepp,Ch..1996.The heat transfer to supercritical carbon dioxide in tubes with mixed convection. Vol 12, PP. 199204.

[15]Wang,Z.,Sun,B., Wang,J., HouL.,2014. Experimental study on the friction coefficient of supercritical carbon dioxide in pipes.International journal of greenhouse gas .control 25, PP. 151-161.

[16] Ameli, A. Afzalifar, A. Turunen-Saaresti,T Backman,J.,2018. Effects of Real Gas Model Accuracy and Operating Conditions on Supercritical $\mathrm{CO}_{2}$ Compressor Performance and Flow Field. ASME. Journal of engineering for gas turbines and power. Vol.140/062603-1.

[17] Ameli, A. Turunen-saaresti,T. backman,J.,2016. Numerical investigation of the flow behaviour inside a supercritical $\mathrm{CO}_{2}$ centrifugal compressor.Turbomachinary technical conference and exposition, GT2016-57481. Korea. pp. 1-8.

[18] Span,R. \& Wagner,W., 1996 .A New Equation of State for Carbon Dioxide Covering the fluid Region from the Triple-Point Temperature to $1100 \mathrm{~K}$ at Pressures up to 800 MPa. vol. 25, no. 6.

[19] Blasius, H., 1913. Das Aehnlichkeitsgesetz bei Reibungsvorgangen in Flussigkeiten. [The Law of Similarity in Friction Processes in Liquids]. VDI Mitt. Forschungsarb., Vol.131, no:PP 1-39.

[20] Monaghan, R.J.,M.A.,1953. Review and Assessment of Various Formulae for Turbulent Skin Friction in Compressible Flow.Technical report, CP. No.142, London: Majesty's station office.

[21] BLASIUS, P. R. H. 1913. Das Aehnlichkeitsgesetz bei Reibungsvorgangen in Flüssigkeiten.

Forschungsheft.Vol. 131,no:PP: 1-41.

[22] Wilcox,D.C,1998. Basic fluid mechanics. $1^{\text {st }}$ ed, USA:D C W industries,Inc.

[23] M. Matsubara, "Direct total skin-friction measurement of a flat plate in zero-pressure- gradient boundary layers," no. April, 2015.
[24] H. Schlichting, "boundary -layer Theory."McGrawhill series in mechanical engineering, Seventh edition.

[25] O. F. Supply, "A Review and Assessment of Various Formulae for Turbulent Skin Friction in Compressible Flow," vol. 141, no. 141.

[26] Samson,N.\& Sidum,A.,2015. Comparative modeling of hull form resistance for three ocean going vessels using methodical series.International journal of engineering and technology .vol.4 no.pp.489-496.

[27] Morrison F. A.,2013. An Introduction to fluid mechanics.first ed. New York:Cambridge University.

[28] Prandtl,L., 1926. Turbulent flow. NACA Technical memorandum, No.435. National advisory committee for aeronautics.

[29] Jensen, M.K, Vlakancic, A.,1999. Experimental investigation of turbulent heat transfer and fluid flow in internally finned tubes, International journal of heat and mass transfer,vol. 42,no:pp.1343-1351.

[30] ANSYS ${ }^{\circledR}$ Academic research CFX, Release 19.1.User guide, Canonsburg.U.S.A 